\title{
Accessible and inclusive mobility for all with individual travel assistance - aim4it
}

\author{
Jan-Peter Nicklas, Nadine Schlüter, Petra Winzer \\ Product Safety and Quality Engineering \\ University of Wuppertal \\ Wuppertal, Germany \\ \{nicklas, schlueter,winzer\}@uni-wuppertal.de
}

\author{
Lars Schnieder \\ Institute of Transportation Systems \\ German Aerospace Center (DLR), \\ Braunschweig, Germany \\ Lars.schnieder@dlr.de
}

\begin{abstract}
Public transportation is a main factor for a reliable mobility in urban and rural areas. Every user group and their specific requirements have to be considered during planning and realization of public transportation services. Hence public transport operators have to ensure a barrier-free public transportation service. Certainly this barrier-freeness still is not realized for every user group, due to the high complexity of public transportation systems. Therefore this paper focuses on a comprehensive Systems Engineering based approach to handle complexity for development of a new individual travel assistance and its integration into existing background systems of public transport operators. This approach is based on several use-cases. One use-case will be focused on for an exemplary system introduction.
\end{abstract}

Keywords-travel assistance, barrier-free transportation, intelligent transportation systems, public transport

\section{INTRODUCTION}

The well-being of a modern society and its economy depends on a functional public transportation system. In the course of a user-centered design of public transportation services the first question to be asked is "What does the passenger want?" Based on the identified needs of today's and tomorrow's passengers as well as available or emerging technologies, researchers, the supply industry, public transport operators as well as public authorities can develop intelligent transportation systems (ITS) that contribute to sustainable urban mobility which is inclusive and accessible for everyone. With the ratification of the convention on the rights of persons with disabilities (UNCRPD) the signing countries commit themselves to support persons with disabilities to live independently and participate fully in all aspects of life. In order to achieve this appropriate measures have to be taken to provide persons with disabilities access, on an equal basis with others, to public transportation and the associated passenger information [1]. Based on the UNCRPD the European Commission adopted a Disability Strategy, which identifies accessibility as one of eight key areas of action. European legislation has been transferred into national laws by the member states [2].

For example the German Passenger Transportation Act [3] legally binds public transportation operators to achieve a fully barrier-free public transport system until 2022. Deaf and hard

Researchproject aim4it - accessible and inclusive mobility for all with individual travel assistance. EU Funding programme Future Travelling (ENT III, Flagship Call 2013), Projectnumber: 4304059 of hearing passengers are one passenger group which currently has not been adequately considered in the design of barrier-free public transport systems. Deaf passengers communicate in sign language which is at least as complex as a spoken language. Currently information on service irregularities in public transportation is not accessible for deaf and hard of hearing passengers because they often have restrictions in reading information in written language. Available data processing and communication capabilities are a promising basis for the development of value-added travel assistance services for this group of passengers. This paper points out how intelligent transportation systems can include smart technologies in order to provide a barrier-free and individual service for everyone, including persons with mobility as well as sensual restrictions. This will be realized by the aim4it (accessible and inclusive mobility for all with individual travel assistance) system architecture and corresponding services which will be described in this paper. First, the current state of the art will be introduced. It will be explained which approaches for traveler assistance and applications are used today for a barrier-free public transportation (section II). On this basis a systematic design approach will be introduced which is based on Systems Engineering (SE) principles to handle complexity. This complexity can be characterized by the number of elements, their relations as likewise the diversity of elements and their relations [19]. Therefore the main processes from the starting point (system definition) to the first service concept, based on defined use-cases, up to the system architecture will be described. All steps are explained by the aim4it system development for individual traveler assistance as an example (section III). Finally results will be summarized and discussed for further developments (section IV).

\section{STATE OF THE ART}

The development of ITS for the public transport domain, like the aim4it travel assistance system, is a complex task. Complexity is driven by the high number of system constituents and the existing relations between them. Design of ITS for the public transport domain has to take the current state of the art into account. 
The state of the art includes the following aspects:

- real time passenger information (A),

- specific representation of traveler information for deaf and hard of hearing passengers (B) and

- travel assistance functions which are based on the available traveler information and provide value-added to passengers (with reduced mobility or sensory restrictions) (C).

These aspects will explained in this section.

\section{A. Real Time Passenger Information (RTPI)}

Passengers using public transport expect information which is available along the complete travel chain which starts with trip planning prior to the trip and ends at the final destination. Today passengers expect that information is tailored to their specific needs, is precise, and of course up-to-date [4, 5]. Special needs for information arise in case of service irregularities [6]. The following basic requirements become even more important in this case.

- Timeliness: Passengers need to get updated information (especially alternative routings) before they will suffer from delay or any other inconveniences [7].

- Personalization: A set of personal attributes describes individual preferences, capabilities (e.g. type and degree of sensory or mobility restrictions) as well as corresponding needs (e.g. type and degree of mobility assistance required). This allows a smart phone app as well as the consumed services (which includes displayed information) to be adapted to the specific requirements of the passengers.

- Relevance: Information provided to the passenger needs to be relevant to him/her. Examples for this are location based services which use position data of travelers for the selective display of information. For example a passenger in public transport is only interested in disruption notifications which are relevant for his specific route.

- Understandability: Information provided to the passenger is linguistic and is perceived by the passenger either in audible or textual format. For this reason special attention should be paid on making passenger information easy to understand. This includes the use of simple syntactic structures as well as the avoidance of synonyms and ambiguities.

Traveler information can be provided on different channels, the most individual and convenient for the customer is his own device (smart phones). Previous standards of passenger information did not adequately address this. In consequence, this leads to reduced functionality for the passenger and proprietary solutions supplied by the industry. Standardized interfaces using IP-based communication have replaced these old standards [8]. By using IP-based web services passenger information can be provided on different channels to the passenger, which includes their own devices.

\section{B. Accessability of RTPI for the deaf and hard of hearing}

Conventional approaches of making passenger information available to deaf and hard of hearing passengers are not suited to the special requirements of passenger information in public transportation. For passengers with hearing aids it is not easy to use their devices in small rooms with lots of background noise. In order to facilitate understanding for this passenger group inductive loops can be used. With this technology voice announcements will be fed directly from the microphone with a special amplifier into an inductive loop. A corresponding loop in the hearing aid or cochlea implant (CI) receives this signal. By doing this background noise will be eliminated and the hard of hearing passenger will get a good signal which facilitates understanding [9].

Another possibility to provide passenger information to the deaf and hard of hearing is to make all audible information routinely made accessible visually by the use of captioning. With captioning the text version of speech is usually displayed on the bottom of a video screen. Captions are particularly useful for people who are deaf or hearing impaired, as well as those who are viewing content in a noisy environment. Most deaf people prefer to communicate in sign language. Sign language has a grammatical structure that is completely different from that of spoken language. The written form of their national language is usually the second language learned for deaf people. For this reason most of them have low reading skills $[10,11]$. Passenger information which is easy to understand and accepted by the community of the deaf and hard of hearing should therefore provide information in sign language.

Translation of spoken or written language into a format understandable by the deaf and hard of hearing can be achieved by sign language interpretation using human interpreters (signers). The signer hears the voices of the hearing or reads the text and renders the message into sign language. A video camera captures the translation which then can be displayed to the deaf and hard of hearing users. With the use of a signer sign language can be used on TV or video. The signer usually appears in the bottom of the screen with the main content being shown full size or slightly shrunk away from the corner. However, this approach is time consuming and cost expensive and therefore not feasible to address the passengers' needs for real time passenger information. Furthermore given the great variety of reasons of disruptions of public transport operations as well as associated impacts it is not possible to pre-record messages for all circumstances in order to have them displayed if that respective situation occurs. The project aim4it will use a sign language avatar. A general feasibility study on the use of sign language avatar documented promising results [12].

\section{Traveler Assistance}

From a technical point of view it is important to include the current state of the art regarding information systems as well as new, innovative concepts like IP-based communication for public transport into the design of a novel travel assistance application. By now smartphones and their multifaceted application potentials have an increasing importance for passengers in public transportation. Today $75 \%$ of all mobile devices in use as well as $96 \%$ of new purchases are 
smartphones [13]. Thereby a bi-directional communication between the passenger and the transportation operator can be realized [14]. The characteristics of mobile devices allow to introduce new travel assistance functions in the public transport domain. Current applications for supporting travelling by mass transportation systems only offer a restricted service. Those apps are provided by public transportation services and available for Android, iOS and Windows Phone. Google Play for example offers 175 different apps for public transportation. Most of them are specialized on one transport system or one city. Those service apps only offer one-directional communication and lack flexibility with respect to route planning especially in case of possible incidents. Furthermore special requests of passengers are not considered. Examples of travel assistance features include the following services.

- Navigation: Based on available routes from traveler information guided navigation can be introduced which is comparable to individual (portable) navigation systems. This navigation is adapted to a trip using public transport and can also include navigation in complex stations [15].

- Interaction: The previously described new set of standards for passenger information indicates the way from passenger information (unidirectional communication to the passenger) to the interaction with the passengers. Now, not only information towards the passenger is considered, also feedback possibilities for the traveler are included. Traveler as well as public transportation networks can benefit from data exchange [16].

- Ticketing: Ticketing is included into travel assistance systems in order to facilitate use of public transport as intransparent ticketing and fares are one of the major obstacles which scare possible customers away from public transport [13].

After introducing the current state of the art, it will be further described how the aim4it travel assistance makes a progress beyond the existing state of the art.

\section{AIM4IT TRAVEL ASSISTANCE}

In this section the development of the aim4it travel assistance system will be described. Fig. 1 shows the four step procedure applied in the project which focuses on traveling by bus. Although the current focus of the aim4it project is on urban transit system, the system can further expanded to other modes of transportation. The focus on industry standards [22] makes the aim4it architecture open to incorporate other modes of transportation (e.g. rail) in the future. Each development step has a corresponding model representation. The model is further elaborated in each development phase. With this methodical approach (including adequate model representations) the aim4it travel assistance system will be explained in more detail.

In the beginning of the SE-based procedure, a black-box approach for the aim4it system definition is used to limit the system (A). Afterwards the derivation of the use-cases is necessary in order to focus the most relevant application cases
(B) and derive requirements for the new system development. In consequence these use-cases have to be the basis for the subsystem development (C). The overall aim4it system concept has to be applied and improved in selected public transportation systems (D). Finally the basis for a further transferability of the concept will be explained.

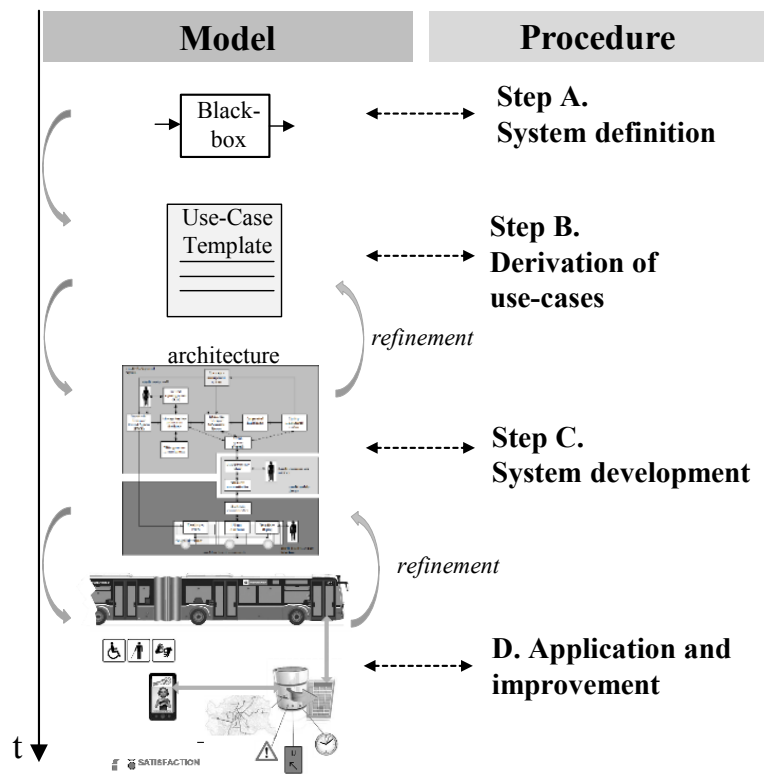

Fig. 1. Combination of model and procedure for the aim4it travel assistance development

\section{A. System definition}

In a first step, based on systems theory, the system scope has to be limited. Therefore the system boundaries have to be clearly defined to focus on the relevant system elements and stakeholders to limit the system's complexity. The limitation of a complex technical system is realized by decomposing the system into a set of subsystems by using a black-box model $[17,18]$. The system inputs and outputs of interest are defined. The desired system-behavior depends on the observer, which is external to the system. As the stakeholders of the aim4it system are versatile the most important stakeholders have to be identified first. First the passengers of public transportation are considered as the most important stakeholder-group of the new travel assistance system. Their requirements can be explained by the request of adequate (timely, correct, precise, understandeable) information in case of any incidents or disruptions of regular operations. The requirements will be gathered and formalized in step $b$, which deals with the usecases. These use-cases are developed and consigned with attributes based on a uniform use-case template.

Focusing on people with disabilities even more requirements regarding understandable, precise and correct information can be identified, e.g. relevant information in sign language or defects of station elevators. Until now the consistent and timely notification of passengers is not a highly prioritized aspect [14]. 


\section{B. Derivation of Use-Cases}

Based on the identified challenges and the system defined, use-cases have to be derived by a template [19]. As shown in $[19,20]$ the environment (processes, locations etc.) has an important influence on system development. By defining usecases related requirements, processes, tasks and environmental conditions can be documented in a pre-defined use-case template [7]. Afterwards activity diagrams have to be developed [21]. These UML-based (unified modelling language) diagrams will not be presented in detail. An overview of the considered use-cases for system development is shown in table I. The use-cases will be further explained below.

TABLE I. DERIVED USE-CASES For THE Aim4IT SyStem

\begin{tabular}{|c|c|}
\hline No. & Use-Cases \\
\hline 1. & Request for connection protection \\
\hline 2. & Incident information in sign language \\
\hline 3. & Request for staff assistance \\
\hline 4. & Feedback function \\
\hline 5. & (Re-)Routing \\
\hline 6. & In-vehicle passenger information based on IBIS IP \\
\hline
\end{tabular}

\section{1) Request for connection protection}

There are only some of the wide range of trips in a public transportation network which are realized by direct connections. Often interchanges are required. To provide a dependable service for passengers transport operators directly monitor connections. If needed, the connecting vehicle can wait for passengers of the feeding vehicle. The request takes into account that passengers with mobility or sensual restrictions need a longer transfer time to the vehicle. Based on this service the connection will be guaranteed and the passenger will be informed in time. The driver of the receiving vehicle will be informed about the prolonged waiting time at the demanded station. In addition connections can be cancelled if no longer required (e.g. due to re-routing) to avoid delay.

\section{2) Incident information in sign language}

All passengers need to get access to detailed and reliable information regarding their trip. To provide such comprehensive information by the travel assistance application for sensory restricted passengers, this information have to be made available in an appropriate way. Barrier-free information includes the media which supplies the information for the passenger. The aim4it project pays special attention to the demands of deaf and hearing-impaired passengers. This passenger group has difficulties in deciphering complex linguistic structures. Therefore the relevant information will be provided by sign language-based avatar videos.

\section{3) Request for staff assistance}

Staff assistance (e.g. by the driver) provides an easier usage of public transportation for passengers with restricted mobility or sensual restrictions. For trip assistance services the passenger must make a reservation by the aim4it travel assistance application. This has to be carried out prior to the trip. The staff member awaits the passenger with mobility or sensual restrictions at the previously defined station and helps the passenger to board the vehicle. At the designated station the staff member helps again by alighting from the vehicle.

\section{4) Feedback function}

To realize a continuous improvement of the transportation system the passengers have to be surveyed. With the aim4it feedback function passengers with sensory restrictions or restricted mobility will be involved in this improvement process. With the help of the assessed performances and opinions of the passengers the public service operator can improve the performances in a precise way. The public transport operators can set up the right priorities for the adaptation of existing facilities and services to the requirements of passengers. In addition gathered requirements can be taken into account for further design and planning of public transportation systems. To realize this actual state of the art customer satisfaction measurement concepts have to be enhanced and combined with real-time IT-technology.

\section{5) (Re-)Routing}

During the trip of a passenger a previously defined trip may become impractical. This may be due to (a) the passenger changing his or her mind about basic parameters of the initial trip, (b) the passenger showing up to late at the start station or missing a connection or (c) irregularities of public transport operations for example in case of delays, cancellation or detours. Once one of these triggering conditions is identified by the mobile phone application a new trip request is initiated. A new route will be generated considering current position of the passenger as well as real time data of public transport operations (including delays and incident information). If rerouting has an impact on another use-case e.g. "Request for staff assistance" information will be updated or the request will be cancelled.

\section{6) In-vehicle passenger information based on IBIS IP}

IP-based communication will be realized by introducing wireless communication between the aim4it application and the transportation vehicle by means of Bluetooth 4.0-interface. Thereby waiting passengers can recognize which line the approaching vehicle is assigned to. Additional information is sent from the vehicle to the application on board. This contains information about the direction of travel, route and stop sequence, real-time information to catch connected services. Also deviations from the scheduled timetable can be sent. With the help of the introduced use-cases 1-6 the system development will be focused on in the next chapter.

\section{System development}

Based on the defined use-cases and the requirements the system development has to be carried out. The system architecture shows the linkage of the aim4it background system, the aim4it application, the aim4it driver interface and associated parts. The main system elements ITIS, ITCS, ICS and the Portal System will be explained afterwards. Based on this the use-case "Incident information in sign language" will be focused on for a more precise presentation.

The Intermodal Transport Information System (ITIS) provides information services for passengers. This interface is 
mainly intended for travelers who want to be informed about their scheduled travel and the connections in between. Mobile devices connect to the ITIS using standardized internet protocol-based communication (TRIAS, Travelers Realtime Information and Advisory Standard). The TRIAS interface consists of a modular set of services where each service has a well described interface. These services can be consumed either directly by the travelers' mobile clients or by immediate systems which could provide additional services for its users [22].

The Intermodal Transport Control System (ITCS) provides information about the current system state for the ITIS. The ITCS has a bi-directional data-link to the vehicles (e.g. by means of professional mobile radio or a public land mobile network) and receives all vehicles' current positions. Furthermore the ITCS supports decision making by the operator and broadcasts information to the vehicles (e.g. prolongation of waiting times for connection protection as well as requests for staff assistance at specific stations). There is no direct connection between the portable devices and the ITIS. A dedicated gateway (Portal system) is introduced to abstract from the specific portable device used by the traveler. This layer of abstraction is required because there are many limitations for portable devices with respect to the energy consumption, the connectivity and also the abilities of the operating system. The Gateway can handle all these limitations. For example the Gateway can use different PushServices for the different smartphone operating systems [22]. By means of the Incident Capturing System (ICS) new messages for the passengers can be entered by the public transport operator. ICS support collection, managing, and publishing of passenger information related to service irregularities in any form or medium [6]. This digital content can take the form of text, announcements or, as in the aim4it project, video files with messages being displayed in sign language using an avatar by the aim4it smartphone app. This key element is used for data entry and data display for the passengers. Therefore the user interface is designed in a usercentered way with respect to the special requirements. Fig. 2 shows the summarized aim4it system architecture.

Focusing on the use-case "Incident information in sign language" for system development in a first step current incident messages have to be investigated. Therefore incident messages, published by the VVS Transit and Tariff Association Stuttgart (Germany) as well as incident messages of Wiener Linien, the public transport operator for the city of Vienna (Austria), have been collected as a basis for analysis regarding the most frequently used ones. In order to adapt the service irregularities documented in the incident capturing system to the special case of passenger information for deaf and hard of hearing passengers a new tool chain is introduced in the background systems of the public transport operators. In order to ease subsequent translation of written text into sign language translation-oriented authoring is applied in the ICS.

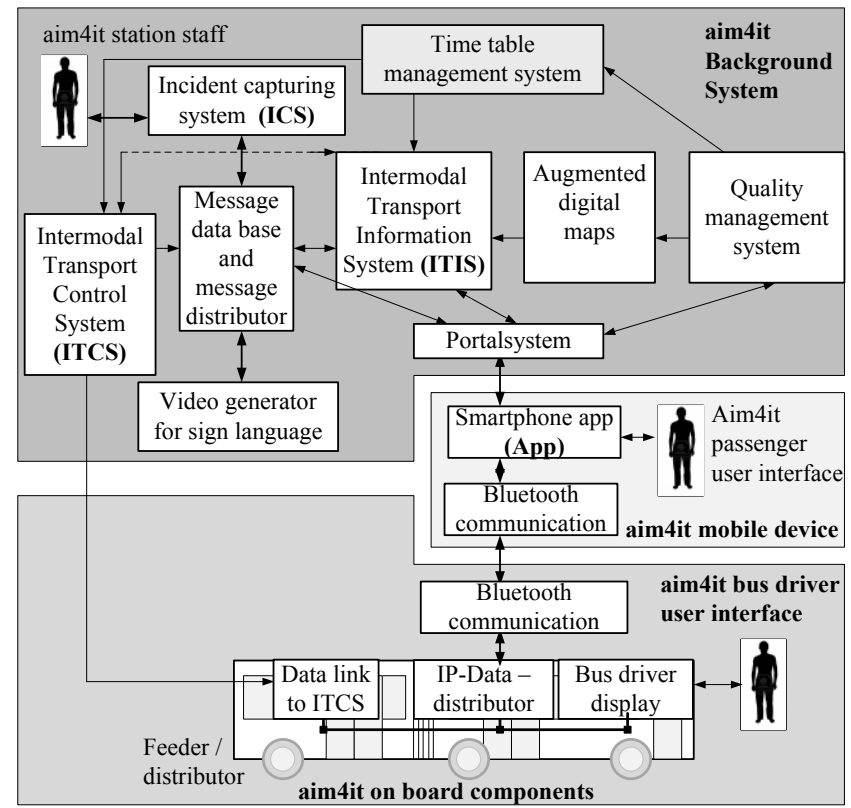

Fig. 2. aim4it system architecture

This means that the user can configure structured incident messages with less complex syntax and a controlled vocabulary. This does not only facilitate the subsequent automatic translation process, but also facilitates understanding of text messages to all other (hearing) passengers. Once the structured incident message is available a video with a sign language avatar will be automatically rendered and stored into a database. The Intermodal Transport Information System (ITIS) determines the affected passengers and distributes to the smart phone of the deaf or hard of hearing passenger with a push service. Once the passenger has been advised of a service disruption along his route, he or she can click on a link and see the incident notification which is shown to him with a digital avatar. An example of an incident notification in sign language of the public transport operator of the city of Vienna (Austria) is shown in Fig. 3.

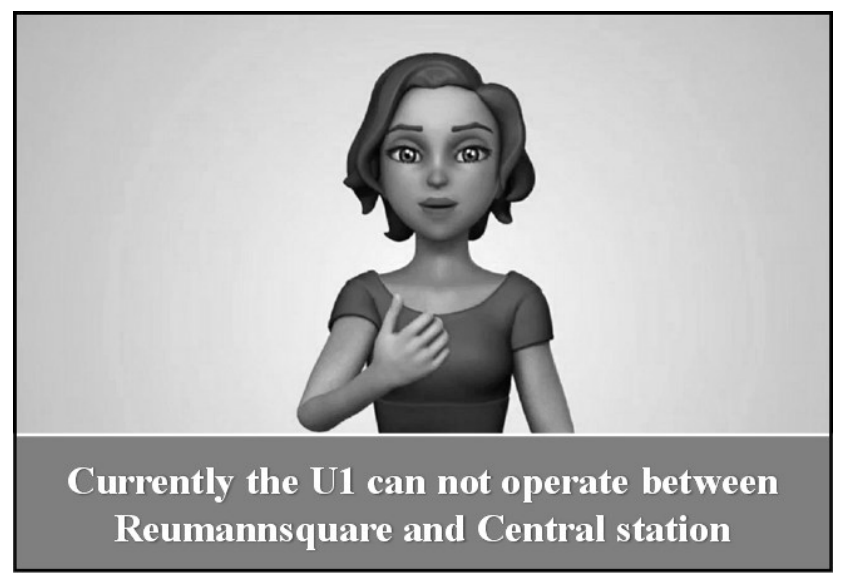

Fig. 3. Video avatar (according to [22]) 


\section{Application and improvement}

The developed system solution will be prototypically implemented during the cause of the project. Based on usecases the test persons will use the prototypical smart phone application and provide feedback for subsequent system improvement. Evaluation of the system solution will include a test group of deaf and hard of hearing. The major research item will be if the sign language avatar can adequately convey the meaning of the incident notification by simultaneously combining hand shapes, orientation and movement of the hands, arms or body as well as facial expressions to fluidly express the speaker's thoughts. By using the aim4it smartphone app, the focused test group can easily express their satisfaction with the supplied services, e.g. by a five star rating how helpful the avatar-based service was. Therewith the service is directly linked to the supplied rating which can be used for improving the services in a feedback loop.

\section{CONCLUSION AND OUTLOOK}

The project aim4it develops a travel assistance application which allows public transport operators to make a significant step towards providing public transport services which are inclusive and accessible. The methodical, SE-based approach pursued in the project allows for iterations in the development of a complex travel assistance application. The standardization documents for IP-based communications in passenger information have been designed in a modular way, so that they can be easily amended and changed. The project aim4it develops additional functions and services which have not been part of the initial standardization project IP-KOM-OEV [8]. The aim4it interface descriptions agreed on within the project consortium will result in work item proposals for subsequent standardization performed by the Association of German Public Transport Companies (VDV). VDV will continuously update its standards and will perform annual reviews of necessary changes to the IP-based communications interfaces to the on-board equipment and the real time passenger information system. Standardization of project results ensures that the aim4it travel assistance concept can be easily transferred to other regions. Recently system design (see step B) has been finalized and the system is being developed. In march 2016 the prototypical system will go into operations in the cities of Vienna (Austria) and Karlsruhe (Germany).

\section{REFERENCES}

[1] United Nations, "Convention on the Rights of Persons with Disabilities" [A/RES/61/106], January, 24 ${ }^{\text {th }}, 2007$.

[2] European Commission, "European Disability Strategy 2010-2020: A Renewed Commitment to a Barrier-Free Europe", $\operatorname{COM}(2010) 636$, Brussels, 15.11.2010.

[3] Federal Ministry of Justice and Consumer Protection, Bundesministerium der Justiz und Verbraucherschutz „Personenbeförderungsgesetz (PBefG)“, http://www.gesetze-iminternet.de/pbefg/, Berlin, 07.08.2013.

[4] K. Daubertshäuser, M. Redmann, M. Gennaro, A. Köhler, "Mehr Echtzeit für alle - Der Rhein-Main-Verkehrsverbund auf dem Weg zur verbundweiten Echtzeitinformation für Fahrgäste, Unternehmen und Aufgabenträger", in Der Nahverkehr 7-8/2013, p. 56 et sqq.
[5] Public transport - Service interface for real-time information relating to public transport operations - Part 3: Functional service interfaces; English version CEN/TS 15531-3:2007.

[6] VDV-Schrift Nr. 720, "Kundeninformationen über Abweichungen vom Regelfahrplan", 07/2011, VDV (Verband Deutscher Verkehrsunternehmen).

[7] J.-P. Nicklas, N. Schlüter, L. Schnieder, P. Winzer, "Entwicklung einer anforderungsgerechten Mobilitätsassistenz für in ihrer Mobilität eingeschränkte Reisende“, in S. Bracke, M. Mamrot, P. Winzer, (eds.), Qualitätsmethoden im Diskurs zwischen Wissenschaft und Praxis, Bericht zur GQW-Jahrestagung 2015 in Wuppertal. Band: 2015,17. Reihe: Berichte zum Qualitätsmanagement. Aachen: Shaker Verlag, 2015.

[8] H. Bandelin, H., T. Franke, R. Kruppa, A. Wehrmann, A. D. Weißer, "Einheitliche Plattform für ÖPNV-Kommunikation auf gutem Weg", in Der Nahverkehr, $7+8 / 2012$, p. 44 et sqq.

[9] U. Rennspieß, G. Freudenreich, "Inklusion - Herausforderung für den Öffentlichen Nahverkehr. Kleine Schritte, große Wirkung: ein Beispiel aus dem Kreis Unna", in Der Nahverkehr 3/2015, pp. 7 - 12.

[10] N. Küng, "Sinnlose Unterhaltung? - Das Unterhaltungserleben gehörloser Personen vermittelt durch audiovisuelle Medien", Dissertation, University Vienna, 2012.

[11] K. Krammer, "Schriftsprachkompetenz gehörloser Erwachsener. Veröffentlichungen des Forschungszentrums für Gebärdensprache und Hörgeschädigtenkommunikation der Universität Klagenfurt” Band 3, Klagenfurt, 2001

[12] M. Kipp, Q. Nguyen, Q.; A. Heloir, "Abschlussbericht Machbarkeitsstudie zur Abschätzung der Nutzungsmöglichkeiten von Gebärdenavataren", Bundesministerium für Arbeit und Soziales, Referat Information, Publikation, Redaktion. Forschungsbericht Sozialforschung 417. Bonn, 2011.

[13] J. Janssen, D. Krings, "Mit Chip und Smartphone - IPS und IPSI vernetzen Handy-Ticket-Systeme in Deutschland", in Der Nahverkehr $1-2 / 2014$, pp. $7-9$.

[14] A. Stelzer, F. Englert, H. Stephan, C. Mayas, "Using Customer Feedback in Public Transprotation Systems", in A. M. Alimi, M., Abed, M. Benaina, M. Benttalima, M., Negi, H.M. Kammoun, M., Wali (eds.), Proceedings of $3^{\text {rd }}$ International Conference on Advanced Logistics and Transport, ICACT, 2014, S.42-47.

[15] C. von Blanckenburg, M. Schiefelbusch, "The "virtual companion" User and provider expectations towards mobility assistance for elderly persons", in F. Busch, M. Spangler (eds.), ITS for Connected Mobility. Selected Paperss from the mobil. TUM 2013 International Scientific Conference on Mobility and Transport, pp. $99-113$.

[16] A. Stelzer, F. Englert, A. Oetting, R. Steinmetz, "Information Exchange for connection dispatching", in EURO - ZEL 2013, 21st International Symposium, 4th - 5th, June 2013, Žilina (Slovakia).

[17] A. Visser, "Measurment-Driven Simulation of Complex Engineering Systems", Amsterdam, Vossiuspers UvA, 2007.

[18] W. R. Ashby, "An introduction to cybernetics", 2. impr. - London, Chapman \& Hall, 1957.

[19] M .Mamrot, S. Marchlewitz, J.-P. Nicklas, P. Winzer, "Using Systems Engineering for a Requirement-Based Design Support for Autonomous Robots", IEEE International Conference on Systems, Man, and Cybernetics, October 5-8, 2014, San Diego, CA, USA, pp. 3146-3151.

[20] R.Fuentes-Fernández, J. J. Gómez-Sanz and J. Pavón, "Requirements Elicitation and Analysis of Multiagent Systems Using Activity Theory" in: IEEE Transaction on Systems, Man, and Cybernetis - Part A: Systems and Humans, Vol. 39, No. 2, March 2009.

[21] A. Cockburn, „Writing Effective Use Cases“, Addison Wesley, 2000.

[22] VDV-Schrift Nr. 430 "Mobile Kundeninformation im ÖV Systemarchitektur", Gesamtbearbeitung 01/2014, VDV (Verband Deutscher Verkehrsunternehmen)

[23] L. Schnieder, G-Tschare, "Passenger information using a sign language avatar", in International Transportation (67) 1, 2015, pp.8-10. 